\title{
Lazer Uygulamaları Öncesinde ve Sonrasında Dikkat Edilmesi Gereken Hususlar
}

\section{Precautions to Take Into Consideration Before and After Laser Applications}

\section{Ibrahim Özmen, Ercan Arca}

Çorlu Asker Hastanesi, Deri ve Zührevi Hastalıklar Bölümü, Tekirdağ, Türkiye Gülhane Askeri Tıp Akademisi, Deri ve Zührevi Hastalıklar Anabilim Dalı, Ankara, Türkiye

\section{Özet}

Yaklașık elli yıldan bu yana dermatolojik hastalıkların tedavisinde kullanılan lazer uygulamaları gittikçe yaygınlașmaktadır. Genel olarak güvenli olmaları ile birlikte, eritem, ödem, dispigmentasyon, ağıı, purpura, bül ve skar olușumu gibi çeșitli istenmeyen yan etkiler, komplikasyonlar ve kazalar için potansiyel teșkil ederler. Bu risklerin ve alınacak önlemlerin uygulayıcı tarafından bilinmesi, hastaya uygun șekilde aktarılması ve hastaların bu konuda bilinçlendirilmesi ile lazer uygulamaları daha güvenli hale getirilebilir. Burada, lazer uygulamalarının etkinlik ve güvenliğini artırmak amacıyla ișlem öncesinde ve sonrasında nelere dikkat edilmesi gerektiğini özetlemeye çalıștık. (Türkderm 2012; 46 Özel Sayı 1: 7-9)

Anahtar Kelimeler: Lazer, önlemler

\section{Summary}

The laser applications which are being used about fifty years for the treatment of dermatological diseases are getting increasingly widespread. Although they are generally safe procedures, they have potential risks for some complications, accidents and undesirable side effects including erythema, edema, dyspigmentation, pain, purpura, blistering and scarring. Laser treatments can be made safer with the knowledge of these risks and precautions to be taken by practitioners and explaining and awareness raising of these to the patients properly. Herein we summarized the points to consider pre- and postoperative precautions in order to improve the efficacy and safety of laser treatments. (Turkderm 2012; 46 Suppl 1: 7-9)

Key Words: Laser, precautions

\section{Giriş}

Geliştirilen yeni teknolojiler ve uygulama tecrübelerinin artması neticesinde, günümüzde dermatolojide lazer kullanımı oldukça yaygınlaşmaktadır. Lazer ve doku etkileşiminin daha iyi anlaşılması ve uygulayıcı deneyimlerinin artması ile dermatoloji alanında lazer kullanımı birçok endikasyon bulur olmuştur. Her ne kadar güvenli ve iyi tolere edilebilir sistemler olsalar da, işlemlerin karmaşıklığı ve uygulama sonrası komplikasyonlar için potansiyel risk oluşturmaları nedeniyle tüm süreç profesyonel şekilde yürütülmeli, işlem öncesinde, uygulama esnasında ve sonrasında gerekli tüm önlemler alınmalıdır.

\section{Genel Güvenlik Önlemleri}

Lazerler yüksek odaklı enerji kaynakları olduklarından, uygulama alanında bulunan kolay tutuşabilecek nesneler, meydana gelebilecek yangınlar için risk oluştururlar. Her ne kadar bu risk eski sistem cihazlarda daha fazla olsa da, oksijen kaynakları, spançlar, masa örtüleri, perdeler, kolay tutuşabilen alkol benzeri dezenfektanlar olası bir yangın için en büyük risk faktörleridir¹. Cilt dezenfeksiyonu için kesinlikle alkol bazlı ürünler kullanılmamalı, cilt su veya serum fizyolojik ile temizlenmelidir. Gözleri kapatmak için kullanılan gazlı bezler alev alma riskine karşı tamamen nemli olmalı, gerekirse uygulama bölgesi içindeki

Yazışma Adresi/Address for Correspondence: Dr. Ibrahim Özmen, Çorlu Asker Hastanesi, Deri ve Zührevi Hastallklar Bölümü, Tekirdağ, Türkiye E-posta: ibrahimozmen@hotmail.com 
veya yakınındaki örtüler de nemlendirilmelidir2. Uygulama bölgesi içinde

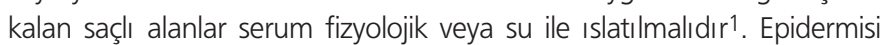
korumak ve anestezi sağlamak amacıyla kullanılan soğutucu sistemlerde de alev almayan türde maddeler kullanılmalıdır³. Uygulama sırasında ortaya çıkabilecek bir yangının, koruyucu gözlükler nedeniyle daha geç fark edilebileceği de unutulmamalıdır. Ayrıca lazer cihazları kullanılmadığı dönemlerde mutlaka bekleme moduna alınmalı ve meydana gelebilecek olumsuzluklar önlenmelidir.

Lazer uygulaması esnasında, retinal maruziyete bağıı kalıcı görme alanı kayı pları nedeniyle hem hasta hem de uygulama odasında bulunan tüm personel, uygulanan lazer tipine uygun koruyucu gözlük kullanmak zorundadır. Periorbital bölge uygulamalarında ise, hastalara tam kornea koruması sağlayan metal kontakt lensler önerilmektedir4. Ayrıca uygulama odasının dış kapısında lazer uygulaması olduğunu, koruyucu gözlük kullanılmadan girilmemesi gerektiğini belirten uyarıcı levhalar asılmalı, uygulama sırasında kapı kilitli tutulmalıdır5.

Elektrik kazaları, her lazer cihazı için kullanılan spesifik elektrik prizleri ile çok büyük oranda elimine edilmiştir. Özellikle Q-anahtarlı lazerlerle dövme silme ve ablatif lazer uygulamaları sırasında ortaya çıkan aerosol halindeki partiküllerin etrafa yayıımını önlemek için özel filtreler içeren aspiratörlerin kullanımı da önerilmektedir ${ }^{1}$.

\section{Hasta Seçimi}

Lazer uygulanacak hastanın beklentileri gerçekçi olmalıdır. Gerçekten uzak beklentiler içinde olan hastalar tedaviye alınmamalıdır. Kalp pili bulunanlarda lazer uygulamaları kontrendikedir. Hastalardan ayrıntılı tıbbi anamnez alınmalı, metal implant bulunan bölgelere uygulama yapılmamalıdır6. Hipertrofik skar ve keloid yatkınlığı olan hastalar daha konservatif tedavi edilmeli, daha düşük akımlar tercih edilmelidir. Koebnerizasyon riski nedeniyle psöriyazis ve vitiligolu hastalar bu konuda uyarılmalı, zorunlu kalmadıkça uygulamadan kaçınılmalıdır. Halen izotretinoin kullanım hikayesi olan hastalara lazer uygulaması yapıımamalı, ablatif lazerler kullanılacaksa en az 1 yıl, diğer lazerlerde tedavinin kesilmesinden sonra en az 6 ay beklenmesi gereklidir7,8. Ancak yapılan çalışmalarda izotretinoin kullanımı sırasında lazer epilasyon uygulamalarının güvenli olduğu da bildirilmiştir9-11. Lazer işlemleri, dolgu ve botulinum toksini gibi başka kozmetik girişimlerle birlikte uygulanabilir ancak genellikle uygulama aralarının en az 15 gün olması önerilmektedir6. Işlem yapılacak bölgede herpes simpleks enfeksiyonu hikayesi olan hastalara, proflaktik antiviral tedaviler uygulanmalı, aktif enfeksiyonu olanlarda işlem uygulanmamalıdır ${ }^{12}$. Aspirin ve oral antikoagülan tedavisi alan hastaların tedavileri, ekimoz riskini artırdığından mümkünse işlemden 10 gün önce kesilmelidir. Postinflamatuar hiperpigmentasyona yatkın, koyu tenli, Fitzpatrick deri fototipi III ve üzerindeki hastalarda uygulama öncesinde birkaç ay kullanılmak üzere hidrokinon ve tretinoin gibi kremler önerilmeli, bu hastalarda daha kısa dalga boyunda lazerler tercih edilmeye çalışılmalıdır12,13. Bronzlaşmış deri lazer tedavisine daha az yanıt vermektedir ve daha yüksek oranda bül ve skar gelişme riski mevcuttur. Bu yüzden yeni bronzlaşmış hastalarda ten rengi normale dönünceye kadar lazer uygulamasından kaçınılmalı ve işlem ertelenmelidir14. Fotosensitif deri hastalığı olan, ya da fotoduyarlandırıcı ilaç kullanım hikayesi olan hastalar daha yakın takip edilmeli, gerekirse tedavi dışında tutulmalıdır. Lazer uygulamalarının gebelik döneminde kullanımı ile ilgili komplikasyon bildirilmemiş olmasına rağmen, ağrı ve distrese neden olması nedeniyle doğum sonrası dönem tercih edilmelidir12. Tüm hastalar için işlem sonrası güneşten koruyucu yöntemler anlatılmalı ve en az SPF 30 ve üzeri güneş koruyucu kullanımı tavsiye edilmelidir. Tüm hastaların potansiyel risk ve komplikasyonları açıklayan aydınlatılmış onamları alınmalı, işlem öncesi ve sonrası fotoğraf kayıtları mutlaka alınmalıdır13.

\section{Vasküler Lezyon Tedavisi}

Erişkinlerde atımlı boya lazerleriyle (PDL) yapılan uygulamalarda anestezi gerekmezken, çocuklarda değişik derecelerde anesteziye intiyaç duyulabilir ${ }^{15}$. Daha büyük çocuklarda uyum kolay sağlanabilirken, infant ve küçük çocuklarda etkin ve güvenilir bir işlem sağlamak için anestezi şarttır. Bu amaçla topikal ve lokal anestezi, sinir blokları, sedasyon veya genel anestezi uygulanabilir15. Özellikle çocukluk dönemi porto şarabı lekesi tedavisinde koopere olunamayan ve prosedürün uyanıkken uygulanamayacağı çocuklarda daha çok genel anestezi tercih edilmektedir16. Özellikle boya lazerleri kullanımından sonra purpura oluşabileceği ve 1-2 hafta içinde gerileyeceği hastaya bildirilmelidir17. Oluşabilecek ağrı soğuk kompres ile azaltılabilir. PDL ile oluşan ağrı hafifleyinceye kadar soğuk uygulama yapılmalıdır. Uzun atımlı boya lazerleri ve potasyum titanil fosfat (KTP) ile oluşabilen reaktif eritem de 1-2 gün içinde gerilemektedir14. Başta KTP olmak üzere vasküler lazer uygulamaları sonrasında nadiren bül ve krut oluşumu meydana gelebilir ve antibiyotikli kremlerle tedavi edilir. Yüz, su ve yıkama ürünleri ile hafif şekilde yıkanabilir ancak krutlanma düzelinceye kadar makyaj yasaklanmalı, hastalara düzenli nemlendirici ve güneş koruyucu krem kullanımı önerilmelidir. Periorabital bölge uygulamalarından sonra oluşabilecek ödem nedeniyle yatarken ilave yastık kullanımı önerilmelidir. Hastalar işlem bölgesini kaşımamaları ve travmatize etmemeleri için uyarılmalıdır18.

\section{Pigmente Lezyon Tedavisi}

Küçük pigmente lezyonların lazerle tedavisinde genellikle anesteziye ihtiyaç duyulmazken, yoğun atımlı ışık kaynakları (IPL) ve Q-anahtarlı lazerlerle epidermal pigmente lezyonların tedavisinde 1-2 saat öncesinde topikal anestezi gerekebilir. Ota nevüs tedavisinde genellikle sinir blokları tercih edilmektedir ${ }^{19}$. Uygulanacak akım, cilt tipi ve lezyona göre belirlenmeli, daha koyu tenli hastalarda düşük akımlar tercih edilmeli, dermal lezyonlarda daha yüksek akımlarla uygulama yapılmalıdır19. Tedaviden sonra yaklaşık yarım saat kadar süren bir beyazlaşma olacağı, bazı alanlarda da yaklaşık 1-2 haftada düzelen krutlanmalar olabileceği hastaya belirtilmelidir. İşlemden sonra soğuk kompres yapılmalı, epitelizan pomadlar uygulanmalı, hastalara düzenli antibiyotikli ve epitelizan kremler ve güneş koruyucu kremlerin kullanımı önerilmelidir.

\section{Lazer Epilasyon}

Lazer epilasyon işlemi öncesinde ağda, cımbız kullanımı önerilmez. Sadece lazer epilasyon işlemi öncesinde uygulama bölgesi traşlanmalıdır. $\mathrm{Bu}$ işlem, uygulama sırasında oluşan kokuyu azaltır ve enerjinin kıl follikülüne daha etkin ulaşmasını sağlar. Aynı zamanda cilt üzerine değen uzun kılların temas ettiği bölgede epidermis hasarı oluşmasını önler ${ }^{12}$. Lazer epilasyon işlemi öncesinde ağda kullanımı, etki mekanizması için gerekli olan kromoforun uzaklaştırıması nedeniyle yapılmamalıdır. Ancak Lehrer ve ark. lazer işleminden 2 hafta önce tüm kıl folliküllerini anagen fazda senkronize etmek için ağda epilasyonu uygulamış ve ağda uygulanan bölgelerde lazer epilasyon etkinliğinin daha yüksek olduğunu göstermişlerdir20. Anagen faza giren kıl folliküllerinin termal hasardan daha çok etkilenmeleri sonucu bu etki elde edilmiştir.

Koyu tenli ve yeni bronzlaşmış bireylerde işlemden birkaç hafta önce başlanan topikal hidrokinon veya tretinoin, oluşabilecek epidermal pigment hasarını azaltmaktadır12,21. 
İşlem sonrası soğuk kompres uygulaması, hem ağrıyı hem de ödemi azaltma konusunda yardımcıdır. Analjezikler geniş alan uygulamaları hariç gereksizdir. İslem yapılan bölgenin hidrasyonunu sağlamak amacıyla düzenli nemlendiriciler kullanılmalıdır. Epidermal hasarlanma olan olgularda topikal antibiyotikler kullanılabilir. Eritem ve ödemin belirgin olduğu hastalarda orta potentli topikal steroidler, mevcut bulgular azalıncaya kadar kullanmak üzere reçete edilebilir. Uygulama sonrasında kaşıma, ovalama gibi her türlü travmadan kaçınılmalı ve kılları kökünden alan epilatör, cımbız ve ağda kullanımı yasaklanmalıdır. Özellikle uygulama sonrası ilk bir haftaya daha çok dikkat etmek üzere, güneşten koruyucu önlemler alınmalı, güneş koruyucu kremler düzenli kullanılmalıdır. Uygulamadan sonraki gün makyaja izin verilebilir. Lazerden etkilenen kılların 7-10 gün içerisinde döküleceği hastaya bildirilmeli, bu durumun kılın tekrar uzadığının bir göstergesi olmadığı hatırlatılmalıdır12.

\section{Lazer ile Cilt Yenileme}

Cilt yenileme için hasta seçilirken açık tenli hastalar tercih edilmelidir. Oral izotretinoin tedavisi alan hastalarda atipik keloidler gelişebildiğinden, lazerle cilt yenileme uygulaması için tedavinin kesilmesinden sonra en az 1 yıl beklenmesi önerilmektedir. Skleroderma hastalarında hastalığın alevlenme riski nedeniyle ablatif uygulamalar yapılmamalıdır22. Ayrıca daha önce radyoterapi görmüş hastalarda adneksiyal yapıların azalmış olması ve epitelizasyon sürecinin gecikebilmesi riski nedeniyle ablatif işlemler uygulanmamalıdır ${ }^{14}$. Koyu tenli hastalarda lazerle cilt yenileme uygulamaları postinflamatuar hiperpigmentasyon açısından riskli iken, fraksiyonel lazerler bu açıdan daha güvenilirdir23. Herpes hikayesi olan hastalara işlemden bir gün önce veya işlem günü oral antiviral tedaviler başlanmalı ve 5 gün sürdürülmelidir24. Anestezi için genellikle 300-400 cm2'yi geçmeyen alanlar için topikal anestezikler önerilmekte ve bir saat öncesinden oklüzyon altında uygulanan kremlerin işlemden hemen önce temizlenmesi tavsiye edilmektedir13. Özellikle geniş alanlarda ablatif uygulamalar sırasında klonidin gibi sedatifler, propofol, midazolam, ketamin ve fentanil gibi anestezikler de kullanılabilir25.

Uygulama sonrası 2-3. günlerde daha belirgin şekilde ortaya çıkan ödemi azaltmak amacıyla 5 günlük oral prednizolon gibi kısa süreli sistemik steroidler yararlı olur26. Yara iyileşmesi sürecinde gözlenen kaşıntı genellikle oral antihistaminiklere iyi yanıt verir. İşlemden sonraki günlerde hastanın yüzünü hassas yıkama ürünleri ve ılık suyla yıkamasına izin verilir. Nemlendirici olarak nonkomedojenik ürünler önerilmelidir13. Uygulama sonrası yara bakımı sırasında uzun süreli okluziv pansumanlar kullanıldığında öncelikle S.aureus ve Paeruginosa başta olmak üzere bakteriyel kolonizasyon oluşabileceği unutulmamalıdır24.

\section{Dövme Tedavisi}

Lazerle dövme çıkarılması için ideal hasta, açık tenli, yakın dönemde bronzlaşmamış ve en az bir yıldır mavi-siyah renkte, monokromatik, amatör dövmesi olanlardır. Tedavi öncesinde dövmeye bağlı skar gelişip gelişmediği ve endürasyon olup olmadığı kontrol edilmeli, yapılacak işleme yön verecek potansiyel alerjik ve granülomatöz reaksiyonlar ortaya konmalıdır. Birçok renkte olabilen dövmelerin lazer tedavisine aynı oranda yanıt vermeyeceği, sarı renk gibi bazı renklerin tam silinemeyebileceği ve tedavi sonunda dövme bölgesinde bulanık bir sınırın kalabileceği hastaya belirtilmelidir. Tedaviye başlamadan önce test atışı yapıımalıdır. Dövmede beyazlama ve noktasal kanama olabileceği hastaya söylenmeli, uygulama sonrası topikal antibakteriyel kremler önerilmelidir27.

\section{Sonuç}

Dermatoloji pratiğinde önemli bir yer edinen lazer tedavilerinin daha etkin, daha güvenli ve komplikasyonsuz şekilde uygulanabilmeleri için, işlem öncesinde gerekli tüm tedbirler alınmalı, hastalarla etkin iletişim içinde olunmalı, işlem sonrası bakım ve koruma tedbirleri ayrıntılı şekilde yapılmalı ve anlatılmalıdır. Ayrıca uygulama hatalarını önlemek amacıyla tüm müdahaleler hekim kontrolünde ve deneyimli kişilerce yapılmalıdır.

\section{Kaynaklar}

1. Tanzi EL, Lupton JR, Alster TS: Lasers in dermatology: four decades of progress. J Am Acad Dermatol 2003;49:1-31.

2. Bean AK, Ceilley RI: Reducing fire risks of the flashlamp pumped 585-nm pulse dye laser. J Dermatol Surg Oncol 1994;20:224.

3. White JM, Siegfried E, Boulden M, Padda G: Possible hazards of cryogen use with pulsed dye laser. A case report and summary. Dermatol Surg 1999;25:250-2.

4. Fader DJ, Ratner D: Principles of CO2/erbium laser safety. Dermatol Surg 2000;26:235-9.

5. Wheeland RG: Basic laser physics and safety. Laser dermatology. Ed. Goldberg DJ. Netherlands, Springer 2005;8-11.

6. Sachdev M, Hameed S, Mysore V: Nonablative lasers and nonlaser systems in dermatology: current status. Indian I Dermatol Venereol Leprol 2011;77:380-8.

7. Stratigos AJ, Dover JS, Arndt KA: Laser therapy. Dermatology. Ed. Bolognia JL, Jorizzo JL, Rapini RP. Philadelphia, Mosby, 2003; 2153-75.

8. Goldberg DJ: Laser dermatology: Pearls and problems. Massachusetts, Blackwell Publishing, 2008;46-61.

9. Cassano N, Arpaia N, Vena GA: Diode laser hair removal and isotretinoin therapy. Dermatol Surg 2005;31:380-1.

10. Khatri KA: Diode laser hair removal in patients undergoing isotretinoin therapy. Dermatol Surg 2004;30:1205-7.

11. Khatri KA: The safety of long-pulsed Nd:YAG laser hair removal in skin types III-V patients during concomitant isotretinoin therapy. J Cosmet Laser Ther 2009;11:56-60.

12. Goldberg DJ, Hussain M: Laser treatment of unwanted hair. Laser dermatology. Ed. Goldberg DJ. Netherlands, Springer, 2005;70-81.

13. Sherling M, Friedman PM, Adrian R, et al: Consensus recommendations on the use of an erbium-doped 1,550-nm fractionated laser and its applications in dermatologic laser surgery. Dermatol Surg 2010;36:461-9.

14. Şahin MT: Lazer Kullanım Öncesi, Sonrası ve Kullanım Sonrasında Alınması Gereken Önlemler. Turkiye Klinikleri J Cosm Dermatol-Special Topics 2009;2:74-8.

15. Cantatore JL, Kriegel DA: Laser surgery: an approach to the pediatric patient. J Am Acad Dermatol 2004;50:165-84.

16. Chen BK, Eichenfield LF: Advances in pediatric dermatologic surgery. Adv Dermatol 2000;16:477-500.

17. Koç E, Tunca M, Kurumlu Z: Telanjiektazik Lezyonların Tedavisinde Lazer Kullanımı. Turkiye Klinikleri J Cosm Dermatol-Special Topics 2009;2:19-25.

18. Lanigan SW: Laser treatment of vascular lesions. Laser dermatology. Ed. Goldberg DJ. Netherlands, Springer, 2005;33-35.

19. DierickX CC: Laser treatment of pigmented lesions. Laser dermatology. Ed. Goldberg DJ. Netherlands, Springer, 2005;56-60.

20. Lehrer MS, Crawford GH, Gelfand JM, Leyden JJ, Vittorio CC: Effect of wax epilation before hair removal with a long-pulsed alexandrite laser: a pilot study. Dermatol Surg 2003;29:118-22.

21. Casey AS, Goldberg D: Guidelines for laser hair removal. J Cosmet Laser Ther 2008;10:24-33.

22. Kimler SL, Semchyshyn N: Ablative and nonablative facial resurfacing. Laser dermatology. Ed. Goldberg DJ. Netherlands, Springer, 2005;85-98.

23. Goel A, Krupashankar DS, Aurangabadkar S, et al: Fractional lasers in dermatology-current status and recommendations. Indian I Dermatol Venereol Leprol 2011;77:369-79.

24. Metelitsa Al, Alster TS: Fractionated laser skin resurfacing treatment complications: a review. Dermatol Surg 2010;36:299-306.

25. Bilaç C, Öztürkcan S: Lazerin Komplikasyonları. Turkiye Klinikleri J Cosm Dermatol-Special Topics 2009;2:79-90.

26. Janik JP, Markus JL, Al-Dujaili Z, Markus RF: Laser resurfacing. Semin Plast Surg 2007;21:139-46.

27. Tüzün Y, Kutlubay Z: Dövmede Lazer Tedavisi. Turkiye Klinikleri J Cosm Dermatol-Special Topics 2009;2:30-5. 